for hepatocellular carcinoma using Yttrium-90 microspheres: a comprehensive report of long-term outcomes. Gastroenterology. 2010;138 (1): 52-64.

3. Ahmadzadehfar $H$, Sabet $A$, Biermann $K$, Muckle M, Brockmann $\mathrm{H}$, Kuhl $\mathrm{C}$, et al. The significance of 99mTc-MAA SPECT/CT liver perfusion imaging in treatment planning for $90 \mathrm{Y}$ microsphere selective internal radiation treatment. Journal of nuclear medicine : official publication, Society of Nuclear Medicine. 2010;51(8):1206-12.

4. Giammarile F, Bodei L, Chiesa C, Flux G, Forrer $\mathbf{F}$, Kraeber-Bodere $\mathbf{F}$, et al. EANM procedure guideline for the treatment of liver cancer and liver metastases with intra-arterial radioactive compounds. European journal of nuclear medicine and molecular imaging. 2011;38(7):1393-406.

5. Gil-Alzugaray $B$, Chopitea $A$, Iñarrairaegui $M$, Bilbao JI, Rodriguez-Fraile M, Rodriguez J, et al. Prognostic factors and prevention of radioembolization-induced liver disease. Hepatology (Baltimore, Md). 2013;57(3):1078-87.
6. Gates VL, Esmail AA, Marshall K, Spies S, Salem R. Internal pair production of $90 Y$ permits hepatic localization of microspheres using routine PET: proof of concept. Journal of nuclear medicine : official publication, Society of Nuclear Medicine. 2011;52(1):72-6.

7. Lenoir L, Edeline J, Rolland $Y$, Pracht $M$, Raoul J-L, Ardisson V, et al. Usefulness and pitfalls of MAA SPECT/CT in identifying digestive extrahepatic uptake when planning liver radioembolization. European journal of nuclear medicine and molecular imaging. 2012;39(5):872-80.

8. Garin $E$, Lenoir L, Rolland $Y$, Laffont $S$, Pracht $M$, Mesbah $H$, et al. Effectiveness of quantitative MAA SPECT/CT for the definition of vascularized hepatic volume and dosimetric approach: phantom validation and clinical preliminary results in patients with complex hepatic vascularization treated with yttrium-90labeled microspheres. Nuclear medicine communications. 2011;32(12):1245-55.

\title{
NGHIÊN CỨU CHU TRÌNH ĐÀO TẠO (LEARNING CURVE) PHẪU THUÂT RÔ BỐT DA VINCI XI ĐIỀU TRI UNG THƯ ĐẠI TRỰC TRÀNG TẠI BỆNH VIÊ̂N K
}

\section{TÓM TẮT}

Mục tiêu: Đánh giá kết quả chu trình đào tạo phẫu thuât rô bốt Da Vinci Xi điều tri ung thư đai trực tràng tại bệnh viện K. Phương pháp nghiên cứu: mô tả tiền cứu. Kết quả: 31 bệnh nhân, 21 nam -10 nữ, Tuổi trung bình 56,7; vị trí ung thư: trực tràng thấp 2 , trực tràng trung bình 6 , trực tràng cao 14 , đại tràng sigma 5 , đại tràng phải 4 ; Phương pháp phấu thuật: cắt cụt trực tràng 2 , cắt đoạn trực tràng 20 , cắt đại tràng sigma 5 , cắt đại tràng phải 4.Thời gian mổ trung bình 139,5 \pm 25 ,8phút, số lượng hạch nạo vét

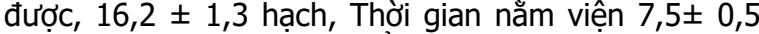
ngày, biến chứng sau mổ $1(4,5 \%)$ độ 1 Clavien, chuyển mổ mở $0 \%$, diện cắt dưới u $100 \%$ không còn tế bào ung thư. Kết luận: Chu trình đào tao mổ rô bốt Da Vinci Xi ung thư đại trực tràng đạt kết quả tốt qua 31 trường hợp phẫu thuật.

Tư khóa: Chu trình đào tạo rô bốt, ung thư đai trực tràng

\section{SUMMARY}

STUDY OF LEARNING CURVE IN ROBOTIC SURGERY FOR COLORECTAL CANCER TREATMENT BY DA VINCI XI SYSTEM AT K HOSPITAL

Purpose: Evaluating the result of learning curve in

\section{*Bênh viên $K$}

Chịu trách nhiệm chính: Phạm Văn Bình

Email: binhva@yahoo.fr

Ngày nhận bài: 21.12 .2020

Ngày phản biên khoa hoc: 25.01.2021

Ngày duyệt bài: 8.2 .2021 robotic surqery treatment colorectal cancer at $\mathrm{K}$ hospital by da Vinci Xi system. Method: prospective and descriptive study. Result: 31 patients, 21 males and 10 females. The averaqe of aqe was 56.7. Location of tumor: lower rectal (2patients), upper rectal (14 patients), siqmoid colon (5 patients), riqht colon ( 4 patients). Type of surqery: abdominoperineal resection ( 2 patients), low anterior resection (20 patients), right colectomy (4 patients). Time of operation was $139.5 \pm 25.8$ minutes. Lenqth of hospitalization was $7.5 \pm 0.5$ day. Postoperative complications: 1 patient (4.5\%) - qrade I of Clavien, conversion surqery none case. $31 / 31$ patients had distal marqin free. Conclusion: The learning curve in robotic surqery for colorectal cancer treatment by daVinci Xi has been successful with 31 patients,

Key words: learning curve in robotic surgery, colorectal cancer.

\section{I. ĐĂT VẤN ĐỀ}

Phẫu thuật sang chấn tối thiểu trong ung thư đại trực tràng (UTĐTT) đã được chứng minh là an toàn và khả thi. Lợi ích của phẫu thuật xâm lấn tối thiểu mang lại khi mổ UTĐTT như giảm đau sau mổ, hồi phục nhanh, ít biến chứng tắc ruột , viêm phổi, sa lồi thành bụng... là những ưu điểm đã được thừa nhận. Những nghiên cứu gần đây cũng đã chứng minh kết quả về măt ung thư học của phẫu thuật xâm lấn tối thiểu tương đướng với mổ mở [2],[3],[5]. Sự phát triển về kỹ thuật ngoại khoa nhờ vào những tiến 
bộ dụng cụ trang thiết bị mới đã giúp cho phẫu thuật viên tiếp cận cách mổ mới ưu việt hơn. Mặc dù có cuộc cách mạng phẫu thuật xâm nhập tối thiểu nhưng nó cũng không được ứng dụng rộng rãi trong những ngày đầu ngay cả ở những nước phát triển. Một trong các lý do là cần một thời gian dài để hoàn thiện chu trình đào tạo (Learning Curves) [4];[5];[6]. Dụng cụ phẫu thuật nội soi thông thường dài, cứng, hình ảnh mố 2D, tư thế mố không tối ưu cho phẫu thuật viên là những hạn chế của phẫu thuật nội soi thông thường. Phẫu thuât rô bốt ra đời sau những thành công khi cắt toàn bộ tiền liệt tuyến đã nhanh chóng được ứng dụng vào mố UTĐTT với những tính năng nổi bật như hình ảnh mổ 3D độ nét cao, độ ổn định không rung lắc của camera, sự mềm dẻo và linh hoạt của dụng cụ rô bốt đã mở ra một cuộc cách mạng mới trong phẫu thuật đại trực tràng. Phẫu thuật rô bốt là một kỹ thuật mồ phức tạp hơn nên nó đòi hỏi một chu trình đào tạo dài, tỷ mỷ với những yêu cầu khắt khe để phấu thuật viện có thể đạt được những tiêu chuẩn cơ bản khi thực hiện phẩu thuật rô bốt [5];[6];[7]. Khái niệm chu trình đào tạo trong phẫu thuật được bắt nguồn từ một thuật ngữ "Learning Curve" do T.P Wright một kỹ sư hàng không người Mỹ đưa ra năm 1936 diễn tả tốc độ sản xuất và chất lượng các bộ phận máy bay tăng lên, giá thành máy bay hạ thẩp xuống khi kinh nghiệm và kỹ năng làm việc của người chế tạo máy bay nâng cao lên nhờ tích lũy theo năm tháng làm việc [4]. Đến năm 1979 Luft là người đầu tiên đưa ra khái niệm "Learning Curve" vào y khoa mô tả mối liên hệ giữa kết quả chữa bệnh và kinh nghiệm tích lũy được trong thực hành lâm sàng của bác sỹ [4];[5];[7]. Hiểu một cách đơn giản là bác sỹ phải trải qua bao nhiêu thời gian và trên bao nhiêu bệnh nhân để đạt được một chất lượng điều trị tiêu chuẩn với từng loại bênh lý hay từng loại kỹ thuật mổ.Tuy nhiên cho tới ngày hôm nay "Learning Curve" vẩn còn nhiều điểm gây tranh luận và cần thống nhất ở các trung tâm y khoa trển toàn câu. "Learning Curve" của phẫu thuật rô bốt cũng được các trung tâm mổ rô bốt trền thế giới tiến hành và đúc rút ra những tiêu chuẩn cơ bản như số lương ca mổ rô bốt tối thiểu là bao nhiêu để phẩu thuật viên mổ đạt được các tiêu chí: tỷ lệ biến chứng, thời gian mổ, thời gian nằm viện, số hạch nạo vét đủ và kết quả gần cũng như kết quả ung thư học tương đương với mổ nội soi thông thường hay mổ mở $[1] ;[2] ;[3] ;[5] ;[6] ;[7]$. Ở Việt nam "Learning Curve" của phấu thuật rô bốt chưa được nghiên cứu nhiều. Xuất phát từ những lý do trên chúng tôi viết bài báo này với mục tiêu: "Đánh giá kêt quả chu trinh đào tạo phẫu thuật rô bốt Da Vinci Xi điều trị ung thư đại trực tràng tại bệnh viện $K^{\prime \prime}$

\section{II. ĐỐI TƯợNG VÀ PHƯƠNG PHÁP NGHIÊN CỨU}

Phương pháp nghiên cứu: nghiên cứu mô tả tiền cứu từ tháng $10 / 2019$ đến $06 / 2020$ với 31 bệnh nhân UTĐTT được phẫu thuật bằng rô bốt Da Vinci Xi tại bệnh viện $K$. Các chỉ tiên nghiên cứu về chu trình đào tạo bao gồm: thời gian mổ, số lượng hạch nao vét, lượng máu mất trong mổ, tỷ lệ chuyển mổ mở, biến chứng trong và sau mổ, thời gian nằm viện, diện cắt dưới u.

\section{KẾT QUẢ NGHIÊN CứU}

Kết quả nghiên cứu: 21 nam, 10 nữ, Tuổi trung bình: 56,7

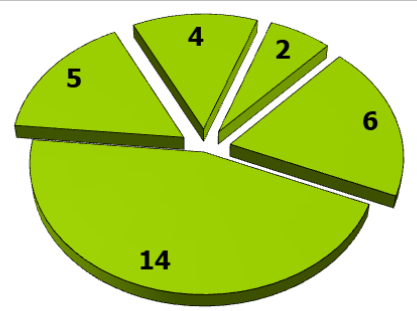

Biểu đồ 1: Vị trí ung thu: trực tràng thấp 2, trực tràng trung binh 6, trực tràng cao 14, đại tràng sigma 5, đại tràng phải 4

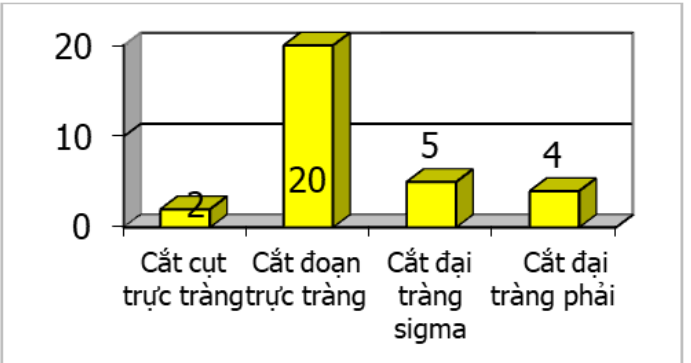

Biểu đồ 2: Phương pháp phẫu thuật: cắt cụt trực tràng 2, cắt đoạn trực tràng 20, cắt đại tràng sigma 5, cắt đại tràng phải 4

Bảng 1: Các tiêu chí của chu trinh đào tạo

\begin{tabular}{|c|c|}
\hline Thời gian mố trung bình & $139,5 \pm 25,8$ phút \\
\hline Số lượng hạch nạo vét được & $16,2 \pm 1,3$ hạch \\
\hline Thời gian nằm viện & $7,5 \pm 0,5$ ngày \\
\hline Tî lệ chuyển mố mở & 0 \\
\hline Tai biến trong mố & 0 \\
\hline Biến chứng sau mố & $1(4,5 \%)$ độ 1 Clavien \\
\hline Diện cắt dương tính & 0 \\
\hline
\end{tabular}

\section{BÀN LUÂNN}

Trong ngoại khoa chu trình đào tạo hay còn gọi là đường cong học tập "Learning curve" mô tả sự hoàn thiện kỹ năng phẫu thuật đạt được 
của phẫu thuật viên thông ca số ca mổ để có được một trình độ cần thiết với kết quả phẫu thuật đủ tiêu chuẩn chất lượng về loại phẫu thuật đó. Năm 1979 lần đầu tiển Luft và cộng sự viết trên tạp chí New Englang journal of Medecine về mối liên quan giữa tỷ lệ tử vong của bệnh nhân và số lượng ca mổ của bệnh viện với loại phẫu thuật đó. Đây được cho là người tiên phong trong lĩnh vực "Learning curve in surgery" [4]. Phẫu thuật rồ bốt là một trong những kỹ thuật cao nhất tại thời điểm hiện nay của phẫu thuật xâm nhập tối thiểu [6];[7]. Câu hỏi đặt ra là với chu trình đào tao của phẫu thuật rô bốt mổ UTĐTT phẫu thuật viên phải trải qua bao nhiêu ca mổ để đạt được trình độ hoàn thiện tiêu chuẩn mổ UTĐTT. Kassite.I thông kê trền PubMed từ 2013 đến 2017 tất cả các bài báo viết về phẫu thuật rô bốt và chu trình đào tạo với từ khóa "Learning curve robotic surgery" với 1065 bài báo chắt lọc lại được 166 bài đủ tiêu chuẩn phân tích về chu trình đào tao. Từ 166 nghiên cứu này chỉ có 17 nghiên cứu về chu trình đào tạo mổ rô bốt UTĐTT. Tác giả cũng nhận xét về sự không đồng nhất các tiêu chuẩn của chu trình đào tao trong các báo cáo này, $\mathrm{cu}$ thể đề cập đến thời gian mổ, biến chứng trong và sau mổ, kết quả sớm về ngoại khoa và kết quả về ung thư. Nhưng tác giả cũng nhấn mạnh $65 \%$ các bài viết về "Learning curve robotic surgery" đề cập tới thời gian mổ [5]. Một báo cáo khác của Soomro.N.A năm 2019 ghi nhận hệ thống toàn bộ các bài báo trên MEDLINE, Embase, Cochrane Library viết về chu trình đào tạo với tổng số 2316 bài viết sàng lọc được 49 bài có đủ các tiêu chí về Learning curve robotic surgery. Tác giả nhận xét phần lớn nghiên cứu về chu trình đào tao thuộc về các lĩnh vực phẫu thuật tiết niệu và phụ khoa, có rất ít bài báo viết về UTĐTT.Trong 49 bài viết này thì có tới $86 \%$ nói về thời gian nằm viện, tỷ lệ biến chứng, tỷ lệ tử vong và số ca mổ rô bốt cần thiết để đạt được "Learning curve Robotic surgery" [7]. Tuy nhiên chúng ta cũng phải hiểu thế nào là khái niệm thành công của chu trình đào tạo? Có rất nhiều tác giả đưa ra định nghĩa về chu trình đào tạo: Jimenez nói rằng bất kỳ phẫu thuật rô bốt nào không phải chuyển mổ mở, không có tai biến trong mổ, không có biến chứng sau mổ, không có tử vong là thành công [5]. Kim lại đưa ra khái niệm thất bại của một cuộc mổ rô bốt là phải chuyển mổ nội soi hay mổ mở vì lý do kỹ thuật, không nạo vét đủ số hạch, diện cắt dưới còn tế bào ung thư, có biến chứng năng sau mổ, chảy máu trong ổ bụng, viêm tụy, rò̀ miệng nối hẹp miệng nối [5].Chúng tôi tìm kiếm và nghi nhận chưa có bài viết nào ở Việt nam nghiên cứu về chu trình đào tạo phẫu thuật rô bốt.

- Số lượng ca mổ cân thiết của Learning curve robotic surgery: đây là một câu hỏi, một khái niệm khó của chu trình đào tạo trong ngoại khoa. Phẫu thuật viên phải thực hiện bao nhiêu ca để có được kỹ năng cũng như kết quả đạt tiêu chuẩn cho kỹ thuâtt mổ rô bốt UTĐTT? Soomro.N.A nhận xét về phẫu thuật rô bốt điều trị UTĐTT dao động từ 0 đến 74 ca trong đó kỹ thuật cắt toàn bộ mạc treo trực tràng là từ 25-30 ca. Tác giả lý giải tại sao lai từ 0 ca tới 74 ca vì với một số trung tâm lớn các phẫu thuật viên đã có nhiều kinh nghiệm về mổ nội soi 3D UTĐTT khi chuyển sang mổ rô bốt sẽ không gặp những thử thách nào về kỹ thuật [7]. Raimondi.P đặt ra câu hỏi trong bài viết của mình là với 23 ca mổ cắt đại tràng phải liệu đã hoàn thành chu trình đào tao mổ rô bốt chưa? Sau khi phân tích CUSUM kết quả của 23 ca mổ của mình, Tác giả kết luận đã hoàn thành chu trình đào tạo mổ rô bốt đại tràng [6]. Một nghiên cứu xem những thách thức và lợi thế nào giữa người dạ và người họ mổ phẫu thuât rô bốt. Có 133 phẫu thuật viên và 73 bác sỹ học mổ được phỏng vấn bằng một bộ câu hỏi. Kết quả tác giả rút ra là thời điểm đào tạo mổ rô bốt thường bắt đầu khi bác sỹ ngoại khoa đã có kinh nghiệm phẫu thuật từ 7 đến 8 năm [6]. Malak.I báo cáo trên 50 bệnh nhân mổ rô bốt UTĐTT qua phân tích chu trình đào tạo bằng CUSUM với các tiêu chuẩn đào tạo, tác giả phân tích và rút ra kết luận chu trình đào tạo hoàn thành khi số ca mổ rô bốt đại trực tràng từ 15 đến 25 ca [2]. Trong nghiên cứu của chúng tôi số ca mổ đạt được là $31 \mathrm{ca}$, tương đương với số lượng "leaning curve in robotic surgery" của các nghiên cứu lớn.

- Thời gian mổ rô bốt: đây là tiêu chuẩn được các nghiên cứu đề cập tới nhiều nhất để phân tích và so sánh. Các thống kê cho thấy khoảng $80 \%$ các nghiên cứu về chu trình đào tạo có đề ra tiêu chuẩn thời gian mổ [4];[5]. Cũng theo Soomro.N.A thời gian mổ rô bốt chu trình đào tạo của phẫu thuất tiết niêuu là $14 \mathrm{ca}$ đối với phẫu thuật viên đã có kinh nghiệm về mổ nội soi, phẫu thuật phụ khoa cắt tử cung là từ 24 ca, cắt toàn bộ mạc treo trực tràng là 25 đến 30 ca [7].Trong báo cáo chu trình đào tạo rô bốt của Raimondi.P với 23 ca cắt đại tràng phải thời gian mổ trung bình là 265,3 phút (180-320) [6]. Bokhari .M.B nhận xét với chu trình đào tạo rô bốt pha 1 từ 15-25 ca thời gian mổ trung bình phẫu thuât đại trực tràng là $214 \pm 74,2$ phút [2]. 
Benizri lại đưa ra kế luận khi chu trình đào tạo mổ rô bốt đại trực tràng thời gian mổ trên 260 phút [5]. Như vậy thời gian mổ là một tiêu chuẩn chứng minh rằng phẫu thuật viên mổ rô bốt đã vượt qua chu trình đào tạo. Trong nghiên cứu của chúng tôi thời gian mổ trung bình là $139,5 \pm 25,8$ phút so với các thống kê systematic review thì thời gian mổ này là đạt yêu câu chu trình đào tạo mổ rô bốt đại trực tràng.

- Biến chứng trong và sau mổ, tỷ lệ chuyển mổ mở: một kỹ thuật mổ được thực hiện theo phương thức nào mà tai biến trong mổ và biến chứng sau mổ cao, tỷ lệ chuyển mổ mở nhiều thì phương pháp mổ đó phải được xem xét lại. Biến chứng, chuyển mổ mở cũng phụ thuộc vào 2 yếu tố: một là yếu tố chủ quan như thể trạng bệnh nhân, giai đoạn bệnh, kích thước khối u, vùng mổ chật hẹp trong tiếu khung...hai là yếu tố khách quan chính là trình độ của phẫu thuật viên. Kassite.I thống kê 166 nghiên cứu về chu trình đào tạo rô bốt có $11 \%$ nói về tiêu chuẩn biến chứng [5]. Renaud định nghĩa một chu trình đào tạo không thành công trong mổ rô bốt khi có 1 tiêu chuẩn biến chứng sau mổ từ độ 1clavien trở lên hay có chuyển mổ mở, trong khi Jimenez thì có biến chứng tử vong hoặc cũng chuyển mổ mở [5]. Benizri lại nêu là có biến chứng trên độ 3 clavien hoặc có chuyển mổ mở [5]. Raimondi.P báo cáo 23 ca cắt đại tràng phải rô bốt tỷ lệ biến chứng là $3 / 23(13 \%)$ độ 1 và độ 2 Clavien, không có trường hợp nào chuyển mổ mở [6]. Năm 2018 Blumberg.D nghiên cứu về cắt đại tràng bằng rô bốt thực hiệ̂n miệng nối trong cơ thể hoàn toàn bởi các phẩu thuật viên đã có kinh nghiệm mổ nội soi. Chỉ với 21 ca mổ rô bốt tỷ lệ biến chứng thấp hơn mổ nội soi thông thường (14\% so với $17 \%)$, không có ca nào chuyển mổ mở và đã đảm bảo vượt qua chu trình đào tạo. Tác giả kết luân phẫu thuật rô bốt cắt đại tràng nối trong cơ thể có tỷ lê biển chứng và chuyển mổ mở trong nghiên cứu đạt được chu trình đào tạo [1]. Với 31 ca phẫu thuật rô bốt đại trực tràng chúng tôi có tỷ lệ biến chứng thấp 1̇a $(4,5 \%)$ đô 1 Clavien, không có ca nào chuyển mổ mở không có tử vong trong vòng 30 ngày sau mổ.

- Số hạch nạo vét được và diện cắt: đây là 2 tiêu chuẩn ung thư quan trong trong phẫu thuật UTĐTT. Kim định nghĩa chu trình đào tạo rô bốt UTĐTT được coi là thất bại khi số lượng hạch nạo vét được dưới16 hạch hoặc diện cắt dưới u còn tế bào ung thư. Park lại đưa ra khái niệm chu trình đào tạo mổ rô bốt không thành công khi nạo vét được dưới 12 hạch và có tái phát tại chỗ sau mổ. Khái niệm chu trình đào tạo thành công của Yang cũng như Kim về số hạch thu được phải tối thiểu từ 16 hạch và diện cắt âm tính [5]. Soomro.N.A thống kê Systematic review từ 68 nghiên cứu chu trình đào tạo rô bốt nếu muốn đạt đủ số hạch theo nguyên tắc ung thư thì số ca mổ phải tối thiểu là $25 \mathrm{ca}$ [7]. Trong 31 ca mổ rô bốt của chúng tôi $100 \%$ diện cắt đều không còn tế bào ung thư, số hạch nạo vét được đảm bảo nguyên tắc ung thư học là $16,2 \pm 1,3$ hạch.

- Thời gian nằm viện: thời gian nằm viện cũng là một chỉ tiêu trong chu trình đào tạo rô bốt. Bokhari.M.B báo cáo về chu trình đào tạo rô bốt đại trực tràng qua 50 ca tác giả nhận xét phải trải qua $25 \mathrm{ca}$ đầu tiên thì thời gian nằm viện của bệnh nhân mới đạt tiêu chuẩn chu trình đào tạo [2]. Kassite.I thống kê trên 166 nghiên cứu về chu trình đào tạo rô bốt với 17 báo cáo của phẫu thuật rô bốt đại trực tràng, trong những báo cáo này thời gian nằm viện là một yếu tố của chu trình đào tạo. Tác giả rút ra nhận xét số ca mổ rô bốt đại trực tràng phải vượt qua trên 15 ca mới đạt được tiêu chuẩn về thời gian nằm viện của bệnh nhân trong chu trình đào tạo [5]. Nghiên cứu của chúng tôi có thời gian nằm viện trung bình $7,5 \pm 0,5$ ngày

\section{KẾT LUẬN}

Qua 31ca phẫu thuật rô bốt chu trình đào tạo mổ rô bốt ung thư đại trực tràng tại bệnh viện $\mathrm{K}$ đạt kết quả tốt với thời gian mổ $139,5 \pm$ 25,8 phút, biến chứng trong và sau mổ thấp $1 \mathrm{ca}$ $(4,5 \%)$ độ 1 Clavien, số lượng hạch nạo vét được16,2 $\pm 1,3$ hạch, diện cắt dưới u 100\% khồng còn tế bào ung thư thời gian nằm viện trung bình $7,5 \pm 0,5$ ngày, không có tử vong trong vòng 30 ngày sau mô.

\section{TÀI LIỆU THAM KHẢO}

1. Blumber.D (2018), Robotic colectomy with intracorporeal anastomosis is feasible with no operative conversions during the learning curve for an experienced laparoscopic surgeon developing a robotics program, Journal of Robotic Surgery, https://doi.org/10.1007/s11701-018-0895-1.

2. Bokhari.B.M, Patel.B.Chirag, Ramos.I.D et al (2011), Learning curve for robotic - assisted laparoscopic colorectal surgery, Surg Endose 25:855 - 860 DOI 10.1007/s00464 - 010 - $1281-x$.

3. Gall.M.H.T, Alrawashdeh.W, Soomro.N et al (2020), Shortening surgical training through robotics: randomized clinical trial of laparoscopic versus robotic surgical learning curves, WWW.bjsopen.com.DOI:10.1002/bjs 5.50353.

4. Hopper N A, Jamison M H, Lewis W G (2007), Learning curves in surgical practice, Postgrad Med J,83:777-779,doi:10.1136/pgmj,2007.057190. 
5. Kasite. I, Bejan-Angoulvant.T, Lardy.H et al (2018), A systematic review of the learning curve in robotic surgery: range and herterogeneity, Surgical Endoscopy, 33:353-365.

6. Raimondi.P, Marchegiani.F, Cieri.M et al (2017), Is right colectomy a complete learning procedure for a robotic surgical program? , J Robotic Surg, Doi 10.1007/s117017-017-0711-3.

7. Soomro.N.A, Hashimoto.A.D, Porteous.A.J et al (2020), Systematic review of learning curves in robot - assisted surgery, BJS Open 4:27-44.

\section{MộT SỐ YẾU TỐ LIÊN QUAN ĐẾN CĂNG THẲNG NGHỀ NGHIỆP CỦA NGƯỜI LAO ĐỘNG TỈNH ĐỒNG NAI NĂM 2020}

\section{TÓM TẮT}

Mục tiêu: Mô tả một số yếu tố liên quan đến tình trang căng thẳng nghề nghiêpp của người lao động tại Cổng ty cổ phân gạch men Y Mỹ, tỉnh Đồng Nai năm 2020. Phương pháp: nghiên cứu cắt ngang. Kết quả: Tỷ lệ căng thẳng nghề nghiêp ở người lao đông là $13,5 \%$. Tỷ lệ này cao hơn ớ nhóm người lao động làm viêc trên 5 ngày/tuần $(18,2 \%)$, thường xuyên phải làm việc với khối lượng công việc vượt quá khả năng của bản thân $(50 \%)$, thường xuyên làm việc với cường độ cao (33,3\%), không được tạo điều kiện học tập $(17 \%)$ so với những người người lao động trong nhóm so sánh với giá trị $\mathrm{p}<0,05$. Nghiên cứu không tìm thấy mối liên quan giữa tình tranng căng thẳng nghề nghiệp với đặc điểm cá nhân của người lao đông. Kết luận: Có mối liên quan có ý nghĩa thống kê giữa tình trạng căng thẳng của người lao động với một số yếu tố như số ngày làm việc/tuân, khổi lượng công việc, cường độ làm việc, cơ hội được học tập.

Từ khóa: Căng thẳng nghề nghiệp, JCQ-V

\section{SUMMARY}

SEVERAL FACTORS RELATED TO

\section{OCCUPATIONAL STRESS OF DONG NAI} PROVINCE'S EMPLOYEES IN 2020

Objective: Describe some factors related to occupational stress of employees at $Y$ My Ceramic Joint-stock company, Dong Nai province in 2020. Method: Cross-sectional studies. Result: The proportion of workers got occupational stress is $13,5 \%$. This proportion is higher in subgroup of workers working for more than 5 days per week $(18,2 \%)$, subgroup of workers usually work under requirements higher than their capability $(50 \%)$, subgroup of workers usually work with high intensity $(33,3 \%)$, subgroup of workers not being given opportunity for higher learning $(17 \%)$, in comparison to workers in control group $(p<0,05)$. The study has not found the significant association between the prevalence of occupational stress and individual characteristics of employees. Conclusion: There was

*Viện Đào tạo YHDP \& YTCC, Đại học Y Hà Nội Chịu trách nhiệm chính: Dương Văn Quân Email: duongquanhmu@gmail.com Ngày nhận bài: 16.12 .2020

Ngày phản biện khoa họ: 26.01.2021

Ngày duyệt bài: 5.2.2021

\section{Dương Văn Quân*, Lê Thị Thanh Xuân*}

a statistically significant relationship between an employee's stress status and several factors such as number of working days / week, workload, intensity of work, opportunity to study.

Keywords: Occupational stress, JCQ-V

\section{I. ĐĂT VẤN ĐỀ}

Căng thẳng nghề nghiệp (hay stress nghề nghiệp) được định nghĩa là sự mất cân bằng giữa yêu câu lao động và khả nẳng lao động [1]. Ở Việt Nam, ngành gạch men đem lại nhiều giá trị về kinh tế - xã hội. Tuy đã có nhiều cải tiến trong guy trình sản xuất, nhưng ngành gạch men vân được coi là một ngành công nghiệp nặng với nhiều khâu sản xuất nguy hiểm, nặng nhọc. Chế độ làm việc ca kíp, cường độ lao động liên tuc và làm viêc trong thời gian dài nhất. Các yếu tố này có thể ảnh hưởng tiêu cực tới NLĐ gây ra căng thẳng nghề nghiệp, làm giảm năng suất lao động. Nhiêu nghiên cứu đã chỉ ra các yếu tố liên quan tới tình trạng căng thẳng nghề nghiệp là rất đa dạng, liên quan chủ yếu tới đăc điểm công việc, quan hệ với đồng nghiệp, các yếu tố gia đình và đời sống xã hội [2]. Tuy nhiên, thực tế lại chưa có nhiều nghiên cứu về mối liên quan này trên đối tượng NLĐ ngành công nghiệp nặng. Do đó, chúng tôi thực hiện nghiên cứu này với mục tiêu: "Mô tả một số yếu tố liên quan đến tình trạng căng thẳng nghề nghiệp của người lao động tại Công ty cổ phần gạch men Ý Mỹ, tỉnh Đồng Nai năm 2020".

\section{II. ĐỐI TƯƠNG VÀ PHƯƠNG PHÁP NGHIÊN CỨU \\ 2.1. Đối tượng nghiên cứu}

- Tiêu chuẩn lựa chọn: Người lao động trực tiếp tham gia vào dây chuyên sản xuất gạch men (bộ phận làm việc trực tiếp).

- Tiêu chuẩn loại trừ: NLĐ làm việc ở các bộ phận gián tiếp như phòng hành chính, nhân sự, quản lý...., vắng mặt tại thời điểm điêu tra.

\subsection{Phương pháp nghiên cứu}

2.2.1. Thiết kế nghiên cứu: Nghiên cứu mô tả cắt ngang

2.2.2. Cỡ mẫu: Toàn bộ NLĐ trực tiếp tham 